\title{
GERENCIAMENTO DE RISCO NO SERVIÇO AEROMÉDICO NO OESTE DO
} PARANÁ

\author{
Liandra Kasparowiz GRANDO ${ }^{1}$; Vanessa COLDEBELLA ${ }^{2}$; Caroline Cattoni \\ JACCARD 3
}

\section{Resumo}

O gerenciamento de risco em saúde é um dos meios para assegurar uma operação eficiente e segura, deste modo, o Serviço Aeromédico base de Cascavel teve por objetivo descrever e identificar os riscos no serviço e propor estratégias de mitigação e gerenciamento destes. Para o seu desenvolvimento valeu-se de uma pesquisa descritiva, de caráter exploratório, dispondo e analisando os dados de forma qualitativa com o eventual auxilio do método quantitativo quando aplicado as demandas de gerenciamento dos riscos através da ferramenta de Análise do Modo e Efeito da Falha, denominada na língua inglesa de Failure Mode and Effect Analysis (FMEA) dando origem ao mapeamento de riscos do serviço buscando a implantação de uma cultura de segurança na equipe, trazendo mais segurança e qualidade para a operação.

Palavras chave: Gerenciamento de riscos, Aeromédico; Failure Mode and Effect Analysis (FMEA), Segurança operacional.

\section{INTRODUÇÃO}

A garantia da qualidade da prestação do serviço de saúde em ambientes complexos vem sendo discutida, na intenção de assegurar uma operação eficiente e segura. Para tal é primordial o Gerenciamento de Riscos em Saúde pela aplicação sistêmica e contínua de políticas, procedimentos, condutas e recursos na avaliação de riscos e eventos que afetam a segurança, a saúde humana, a integridade profissional, o meio ambiente e a imagem institucional (USP, 2010).

A equipe de bordo deve estar preparada e apta para tomada de decisão em situações adversas bem como gerenciar os riscos uma vez que não é possível elimina-los, o que pode ser desenvolvido através da identificação dos mesmos na operação aeromédica. Visando o gerenciamento de risco e segurança da operação no Serviço Aeromédico base de Cascavel o presente estudo tem por objetivo descrever e identificar os riscos e propor estratégias de mitigação e gerenciamento dos mesmos bem como a implantação de uma cultura de segurança na equipe.

Enfermeira, Especialização em Transporte Aeromédico e Medicina Aeroespacial - Enfermeira assistencial do serviço aeromédico base de Cascavel/Pr. e-mail: liandrakg@gmail.com. Artigo de conclusão da pós graduação em Transporte Aeromédico e Medicina Aeroespacial - CENSUPEG.

2 Enfermeira, Especialização Transporte Aeromédico e Medicina Aeroespacial -Enfermeira assistencial do serviço aeromédico base de Cascavel/Pr. e-mail: vanessacolde@gmail.com

3 Professora orientadora da Pós-Graduação de Transporte Aeromédico e Medicina Aeroespacial do Grupo CENSUPEG. E-mail: carolcattonijaccard@gmail.com 


\section{METODOLOGIA}

Trata-se de uma pesquisa descritiva, de caráter exploratório, dispondo e analisando os dados de forma qualitativa com o eventual auxilio do método quantitativo quando aplicado as demandas de gerenciamento dos riscos através da ferramenta de Análise do Modo e Efeito da Falha (FMEA) dando origem ao mapeamento de riscos do serviço Aeromédico base de Cascavel.

\section{FUNDAMENTAÇÃO TEÓRICA}

O gerenciamento de risco tem sua origem na área militar, aeronáutica e na indústria pela aplicação de um processo estruturado, identificando e avaliando os riscos e a incerteza associada, desenvolvendo estratégias de enfrentamento e a sua implementação através de atividades preventivas e de controle, mantendo uma postura proativa diante dos riscos identificados (BRASIL, 2017).

O campo da saúde é muito amplo e o trabalho ocorre em diferentes cenários e requer o gerenciamento de métodos específicos para a identificação dos riscos conforme cada ambiente. Um desses cenários é o do serviço aeromédico que tem suas particularidades inerentes à aviação e devem seguir critérios de Segurança Operacional, sendo um conjunto de medidas, conscientemente implantadas com o objetivo de identificar, gerenciar, reduzir ou minimizar os riscos de operações aeronáuticas, envolvendo todos os atores envolvidos direta ou indiretamente na operação, considerando o risco e perigo exposto. (RODEGUERO; BRANCO, 2013).

Em Cascavel a implantação do serviço aeromédico, deu-se em janeiro de 2014, uma parceria do Governo Estadual pela Rede Paraná Urgência e o Consórcio Intermunicipal de Saúde do Oeste do Paraná (CONSAMU), sendo a primeira base de atendimento exclusivo da saúde no país, prestando atendimentos de nível primário e secundário. Conta com uma aeronave asa rotativa (helicóptero) obedecendo as normas estabelecidas pela ANAC, e conforme a Portaria do MS 2048/02 o atendimento visa chegar o mais precocemente a vítima após o agravo a saúde que possa levar a sequelas e ou morte, prestando um atendimento qualificado e ágil da origem ao destino, contando com uma equipe treinada para avaliar as condições da vítima, realizar procedimentos para a manutenção da vida e decidir qual a melhor unidade hospitalar para o atendimento definitivo (BRASIL, 2010).

Pelas particularidades envolvidas nas operações aeromédicas o Processo de Gerenciamento de Riscos surge como uma ferramenta eficaz para identificação, avaliação e controle, colocada à disposição da equipe para a prevenção de 
acidentes (BENI, 2011). Para cada perigo há pelo menos um risco. Depois da identificação dos mesmos deve ser feita a classificação. Métodos diversos vêm sendo utilizados para a análise de risco dentre esses destaca-se a Análise do Modo e Efeito da Falha (FMEA-Failure Mode and Effect Analysis), que se caracteriza por ser não estatística, crítica, sistematizada, proativa, prospectiva e contínua (WHO, 2008). Desenvolvida por engenheiros e inicialmente empregada em indústrias de alto risco como a aviação e energia nuclear, a FMEA é, na atualidade, usada na avaliação proativa e melhoria da segurança de processos complexos de cuidados a saúde, e recomendada por organizações internacionais, tais como Joint Commission, Institute for Healthcare Improvement e Institute for Safe Medication Practices (BRASIL, 2017). Pelas características desse instrumento e pela complexidade da operação aeromédica foi 0 método escolhido para 0 desenvolvimento do gerenciamento de risco do serviço base de Cascavel.

A primeira etapa na FMEA é a realização de sessões sistemáticas de brainstorming, onde cada atividade desenvolvida no processo é analisada, identificando-se todos os possíveis modos, efeitos e causas potenciais de falha. Os mecanismos de controle existentes para evitar os modos potenciais de falha, tanto direcionados para a prevenção como para a detecção também são verificados. Neste momento a equipe utiliza de suas experiências profissionais e de documentos existentes como fonte de informação (SILVA, 2008).

Assim foram selecionados para análise de gerenciamento os seguintes procedimentos de risco na operação aeromédica na base Cascavel com suas respectivas justificativas que apoiaram a equipe a selecioná-los: Pouso e decolagem; Condições meteorológicas desfavoráveis; Ruídos e vibrações; Segurança do paciente; Condição clínica do paciente. Após esta etapa, foram determinados os índices de gravidade $(G)$ tabela do efeito do modo de falha, de probabilidade de ocorrência (O) da causa potencial de falha e de detecção (D) dos controles, constituídos de notas que vão de um a dez, atribuídas pelos profissionais e embasadas em seus conhecimentos e vivências, conforme escalas norteadoras (SILVA; TEIXEIRA; CASSIANI, 2008). Na sequência foi determinado por meio do número de prioridade de riscos (NPR), obtido pela multiplicação de $\mathrm{G}, \mathrm{O}$ e $\mathrm{D}$ podendo ir de um a mil, obtendo um escore baixo, médio, alto e muito alto para cada processo avaliado (tabela 4) (BRASIL, 2017).

Para o registro do gerenciamento dos riscos encontrados no serviço utilizou- 
se a planilha FMEA onde aplica-se os passos: 1) processo a ser analisado; 2) modos de falha; 3) efeitos; 4) possíveis causas; 5) prevenção ou detecção; 6) índices de gravidade do efeito; 7) probabilidade de ocorrência; 8) detecção do modo de falha; 9) valor de NPR; 10) ações preventivas e corretivas elaboradas pela equipe.

Com a utilização dessa ferramenta no gerenciamento de riscos na base do Serviço aeromédico de Cascavel, foi possível identificar alguns dos riscos inerentes as missões, contribuindo com ações preventivas de enfrentamento, proporcionando mais segurança e qualidade na operação.

\section{CONCLUSÃO}

Considerando a complexidade do Serviço Aeromédico, a base de Cascavel vem buscando uma assistência mais segura através do Gerenciamento de Riscos, para tal selecionou o instrumento ferramenta de Análise do Modo e Efeito da Falha FMEA, mapeando os riscos identificados e tornando-se um norteador na prevenção e mitigação dos mesmos.

Evidenciou-se que mais estudos acerca do tema precisam ser desenvolvidos, diante da necessidade de referências para aplicabilidade nos serviços de remoção aeromédica de acordo com cada realidade, beneficiando o paciente e equipe de bordo, pois a Gestão de riscos traz segurança operacional.

\section{REFERÊNCIAS}

BENI, Eduardo. Proposta de metodologia de gerenciamento do risco operacional para missão com helicóptereos. Acesso em 1 de março de 2011. https://www.pilotopolicial.com.br/proposta-de-metodologia-de-gerenciamento-do-

Risco-operacional-para-missao-com-helicopteros/

BRASIL. Agencia nacional de vigilância sanitária. Gestão de riscos e investigação de eventos adversos relacionados à assistência à saúde. Brasília: Editora Ministério da Saúde, Anvisa 2017.

BRASIL. Ministério da Saúde. Diretrizes e Protocolos de atendimento aeromédico. Brasília: Editora Ministério da Saúde, 2010.

RODEGUERO, Miguel Angelo; BRANCO, Humberto. Gerenciando o risco a aviação geral. São Paulo: Editora. Bianch, 2013.

SILVA, Ana Elisa Bauer de Camargo; TEIXEIRA, Thalyta Cardoso Alux; CASSIANI, Silvia Helena De Bortoli. Ferramentas utilizadas para gestão de riscos: análise do modo e efeitos da falha e análise de causa raiz. In: Feldman LB. Gestão de risco e segurança hospitalar. São Paulo: Martinari; 2008, vol. 1, p. 309-24.

USP. Cartilha de gerenciamento de riscos: comitê de segurança do paciente. Ribeirão Preto: Editora USP, 2010.

World Health Organization (WHO). Alianza Mundial para la seguridad del paciente. La investigacion em seguridad del paciente: Mayor conocimiento para una atencion mas segura.Genebra, 2008. 